\title{
3-D Synthetic Aperture High Volume Rate Tensor Velocity Imaging Using 1024 Element
} Matrix Probe

Makouei, Fatemeh; Asl, Babak Mohammadzadeh; Jørgensen, Lasse Thurmann; Tomov, Borislav Gueorguiev; Stuart, Matthias Bo; Jensen, Jørgen Arendt

\author{
Published in: \\ 2020 IEEE International Ultrasonics Symposium (IUS)
}

Link to article, DOI:

10.1109/IUS46767.2020.9251377

Publication date:

2020

Document Version

Peer reviewed version

Link back to DTU Orbit

Citation (APA):

Makouei, F., Asl, B. M., Jørgensen, L. T., Tomov, B. G., Stuart, M. B., \& Jensen, J. A. (2020). 3-D Synthetic Aperture High Volume Rate Tensor Velocity Imaging Using 1024 Element Matrix Probe. In 2020 IEEE International Ultrasonics Symposium (IUS) IEEE. https://doi.org/10.1109/IUS46767.2020.9251377

\section{General rights}

Copyright and moral rights for the publications made accessible in the public portal are retained by the authors and/or other copyright owners and it is a condition of accessing publications that users recognise and abide by the legal requirements associated with these rights.

- Users may download and print one copy of any publication from the public portal for the purpose of private study or research.

- You may not further distribute the material or use it for any profit-making activity or commercial gain

- You may freely distribute the URL identifying the publication in the public portal 


\title{
3-D Synthetic Aperture High Volume Rate Tensor Velocity Imaging Using 1024 Element Matrix Probe
}

\author{
Fatemeh Makouei ${ }^{1,2}$, Babak Mohammadzadeh Asl ${ }^{1}$, Lasse Thurmann Jørgensen ${ }^{2}$, Borislav Gueorguiev \\ Tomov $^{2}$, Matthias Bo Stuart ${ }^{2}$, Jørgen Arendt Jensen², IEEE Fellow \\ ${ }^{1}$ Tarbiat Modares University, Tehran, Iran \\ ${ }^{2}$ Center for Fast Ultrasound Imaging, Department of Health Technology, \\ Technical University of Denmark, DK-2800 Lyngby, Denmark
}

\begin{abstract}
Tensor velocity imaging (TVI) in a 3-D volume is investigated through simulations and experiments conducted using a Vermon $3 \mathrm{MHz} 1024$ element phased array (Vermon S.A., Tours, France) along with the experimental scanner SARUS. The flow-rig with a parabolic flow profile was positioned along the $x$ direction. The data is acquired by a recursive interleaved synthetic aperture sequence with 5 emissions at a pulse repetition frequency of $5 \mathrm{kHz}$ to produce estimates at a volume rate of $500 \mathrm{~Hz}$. A directional transverse oscillations velocity estimator based on cross-correlation is used to estimate the velocity components in the three Cartesian directions. The simulations were performed at peak velocities $\left(v_{p}\right)$ from $0.1 \mathrm{~m} / \mathrm{s}$ to $1 \mathrm{~m} / \mathrm{s}$. At $v_{p}=1 \mathrm{~m} / \mathrm{s}$, the estimates were achieved with relative mean bias (RB) less than $-13.3 \%$ and relative mean standard deviation (RSD) less than 5\%. The experiments were conducted at a $v_{p}$ of $0.25 \mathrm{~m} / \mathrm{s}$, and the estimates for $\left(v_{x}, v_{y}, v_{z}\right)$ were obtained with RBs of $(5.35,3.02,1.00) \%$ and RSDs of $(5.03,4.87,1.27) \%$.
\end{abstract}

\section{INTRODUCTION}

Two-dimensional (2-D) vector flow imaging (VFI) reveals the in-plane velocity, whereas the blood flow in the body is inherently in 3-D. Tensor velocity imaging (TVI), defined as estimation of the $3-\mathrm{D}$ velocity in a volume over time, provides the full flow information. To get the 3-D TVI, it is possible to use row-column addressed probes [1]-[3], matrix probes [4]-[8], or multiple probes [9]-[11]. The capability at electronical beam steering at any direction is one of the main advantages of matrix probes [12]. Such a probe has been used to estimate the volumetric velocity in-vivo [13]. However, the developed technique provided estimations of only the axial velocity in the whole volume. In another work, the authors used a 1024 element matrix probe to get a 3-D velocity estimation by a single plane wave emission [4]. However, the small aperture size limited the captured volume size. In [5], volumetric velocity estimation was achieved at a volume rate of $50 \mathrm{~Hz}$ by gating over multiple heart beats, which leads to the prerequisite of a steady heartbeat and sometimes breathhold. The approaches that cover the volume through lines, planes, or gating have slow volumetric coverage. However, in [14], continuous data was provided by using recursive interleaved synthetic aperture (SA) VFI. The 3-D velocity vectors were estimated by emitting 5 interleaved ultrasound pulses at a pulse repetition frequency $\left(f_{p r f}\right)$ of $15 \mathrm{kHz}$, and employing a directional transverse oscillations (TO) SA velocity estimator.

This paper is a continuation of previous work [14], and evaluates the performance of the estimator on measured data. A 3-D version of the TO method with a recursive interleaved SA sequence [14] is used in simulations using Field II [15], [16], and a flow-rig set-up to estimate the tensor velocity at a high volume rate of $500 \mathrm{~Hz}$. This approach provides full flow information with high accuracy and is applicable for diagnosing cardiovascular diseases. The provided high volume rate leads to the opportunity of volumetric imaging of complex flow and vortices.

Section II presents the method, Section III gives the details of the simulation and measurement set-ups, and Section IV reports the obtained results along with the relevant discussions. Finally, Section V concludes the paper.

\section{METHOD}

This section describes the recursive interleaved sequence used for data processing and explains the velocity estimator. The principles of interleaved SA and recursive interleaved SA are explained in details in [17] and [18]. Interleaving repeats each emission in the sequence twice, and constructs the HRI pairs by separately combining the odd and even emissions. By recursive imaging the HRIs are updated with each emission. Fig. 1 is adapted from [18] to illustrate the recursive SA sequence with 4 interleaved emissions. One low resolution image (LRI) 


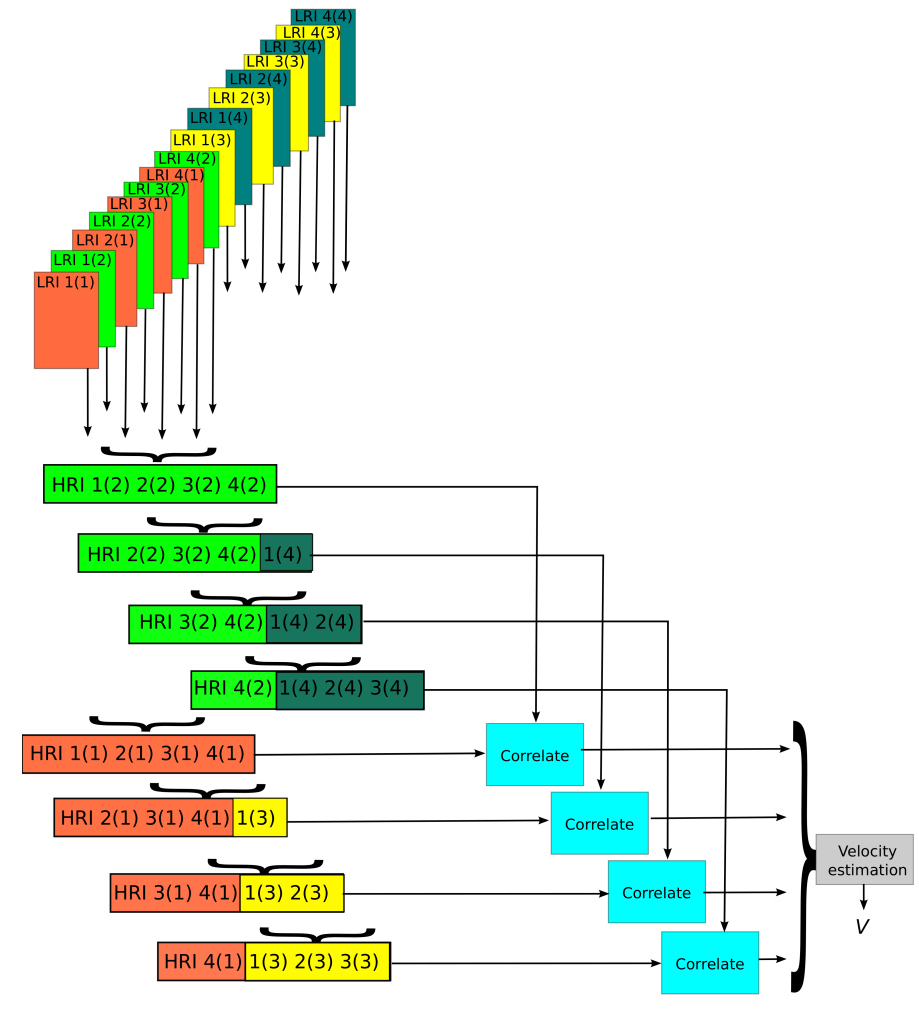

Fig. 1: Illustration of the recursive SA emission sequence where a new HRI is created after each pulse emission. The first number in sequence definition is the emission (virtual source), and the second number in parentheses is the sequence number used. Adapted from [18]

is formed by each emission and 4 interleaved LRIs are summed together to produce a high resolution image (HRI). In Fig. 1, the first number is the emission (virtual source), and the second number in parentheses is the sequence number used. A new HRI is created for each emission. In this work, 3-D volumes are produced instead of 2-D images. Five interleaved low resolution volumes (LRVs) are summed to produce each high resolution volume (HRV). The HRVs are updated after every emission as presented in Fig. 1. One of the main advantages of the recursive interleaved SA is the imaging of the flow at a very high volume rate equal to the $f_{p r f}$. The two HRVs are only $T_{p r f}=1 / f_{p r f}$ seconds apart by interleaving the two sequences, and so the highest detectable velocity is independent of the number of emissions in the sequence [18]. Three lines are beamformed through each individual image point to perform the velocity estimation at every single point in the whole insonified volume in front of the probe. The lines are focused in the $x$, $y$, and $z$ directions. Double-peak Hanning apodizations along the $x$ and $y$ directions are employed in receive to generate a transverse oscillation in respective directions.
Prior to doing correlation to estimate $v_{x}$ and $v_{y}$, the axial oscillation is removed from the signal [18]. Then, the corresponding lines in $H R V i$ and $H R V i+1$ ( $i$ is odd) are correlated, and the correlation functions calculated at each pair of HRVs are averaged. Furthermore, temporal averaging is obtained by averaging over correlations of 16 sets of HRVs. The velocity is estimated as

$$
v=\Delta x \cdot f_{p r f},
$$

where, $\Delta x$ is the spatial shift found by the decorrelation estimator.

\section{Set-UP, Processing, AND Metrics}

The simulations were performed in Field II [15], [16]. A flow-rig at a depth of $20 \mathrm{~mm}$ with a parabolic flow profile with different peak velocities of $[0.1,0.25,0.5,1]$ $\mathrm{m} / \mathrm{s}$ was simulated. The flow was along the $x$ direction of the transducer $\left(\left[\theta_{x z}, \theta_{x y}\right]=\left[\begin{array}{ll}90 & 0\end{array}\right]^{\circ}\right)$, where $\theta_{x y}$ and $\theta_{x z}$ are the rotation of the probe against flow direction in the $x y$ and $x z$ planes. The emitted pulse was a $3 \mathrm{MHz}$, 3 -cycle sinusoid. The sampling frequency $\left(f_{s}\right)$ was 70 $\mathrm{MHz}$.

The measurements used the Vermon 1024-element fully addressed 2-D transducer (Vermon S.A., Tours, Franc) [19] in combination with the experimental ultrasound scanner SARUS [20]. The probe was positioned above a rubber tube $(\varnothing=12 \mathrm{~mm})$ at a depth of $18 \mathrm{~mm}$, and blood mimicking fluid with a parabolic flow profile was circulated by a controllable flow pump. The volume flow was recorded by a Danfoss Magnetic flow meter MAG 1100 (Danfoss, Nordbor, Denmak), and the flow rate was adjusted to provide a peak velocity of 0.25 $\pm 0.01 \mathrm{~m} / \mathrm{s}$. The beam-to-flow angle was $90^{\circ}$. Each HRV was made with 5 interleaved emissions (from virtual sources behind the transducer with steering angles of $0, \pm 6^{\circ}$ in $x$, and $\pm 6^{\circ}$ in $y$ directions) at an $f_{p r f}$ of 5 $\mathrm{kHz}$ by the recursive interleaved SA sequence. The setup parameters are summarized in Table I.

The separation in time between the correlated HRVs is $1 / f_{p r f}$, and a new estimate is produced for every other high resolution volume. Echo cancelling was performed by subtraction of the mean value of the HRVs from the individual HRVs. The data were processed offline, and the 3-D cross-correlation TO velocity estimator was used to produce the $v_{x}, v_{y}$, and $v_{z}$ components simultaneously in the full volume. Corresponding lines at pairs of two HRVs were correlated, and the correlation functions of 16 pairs were averaged to produce one velocity profile estimate. 
TABLE I: Set-up parameters

\begin{tabular}{l|c|c|c} 
Parameter & Value & Unit & Variable \\
\hline No. elements & 1024 & & \\
Centre frequency & 3.0 & $\mathrm{MHz}$ & $f_{0}$ \\
Cycles in excitation & 3 & & \\
Speed of sound & 1480 & $\mathrm{~m} / \mathrm{s}$ & $c$ \\
Transmit apodization & von Hann & & \\
Element pitch & 0.3 & $\mathrm{~mm}$ & $P_{i}$ \\
Pulse repetition frequency & 5 & $\mathrm{kHz}$ & $f_{p r f}$ \\
No. emissions & 5 & & \\
Transmit F-number & -2 & & \\
Steering angles & $0, \pm 6^{\circ}$ in $x$, and $y$ & & \\
Vessel diameter & 12 & $\mathrm{~mm}$ & $\varnothing$ \\
Measurement depth & 18 & $\mathrm{~mm}$ & \\
Simulation depth & 20 & $\mathrm{~mm}$ &
\end{tabular}

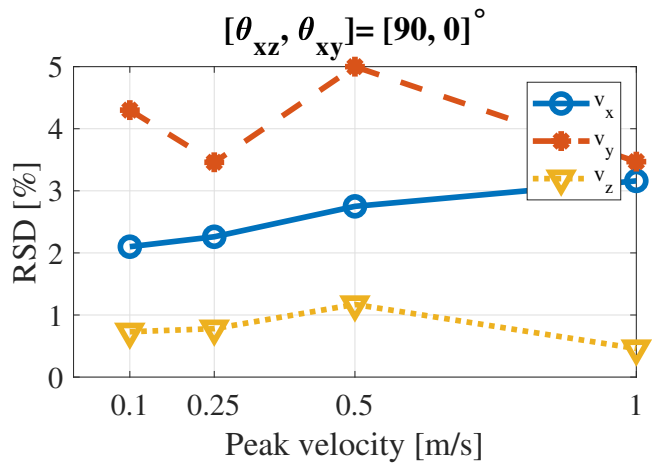

(a)

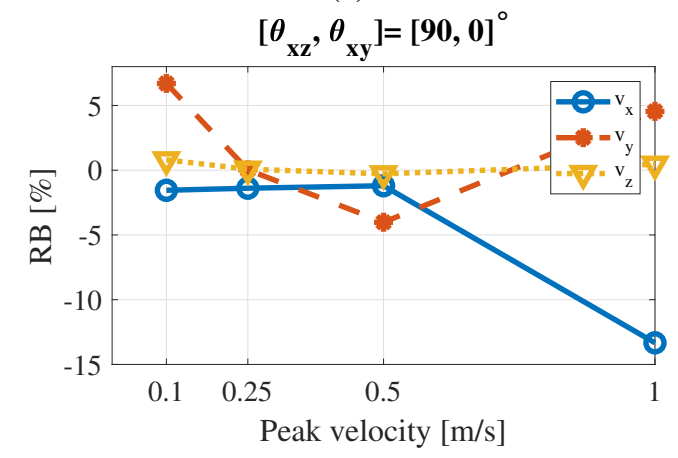

(b)

Fig. 2: Performance metrics for the simulation results at different peak velocities present in a flow phantom positioned at $\left[\theta_{x z}, \theta_{x y}\right]=\left[\begin{array}{ll}90 & 0\end{array}\right]^{\circ}$. The solid blue line represents the metrics for $v_{x}$, the dashed red line for $v_{y}$, and the dotted yellow line shows $v_{z}$. (a) RSD, (b) RB.

the vessel lumen.

\section{RESULTS AND DISCUSSION}

A flow phantom with parabolic flow profile and peak velocities of $\left[\begin{array}{llll}0.1 & 0.25 & 0.5 & 1\end{array}\right] \mathrm{m} / \mathrm{s}$ are simulated to investigate the performance of the estimator at different peak velocities. RSD and RB metrics at the central $90 \%$ of the profiles as a function of peak velocity present in the flow phantom are reported in Fig. 2. Overall, the RSD values do not increase markedly for increasing peak velocity, whereas there is a rise in RB. It should be noted that, ideally, the highest detectable velocity is proportional to $v_{\max } \simeq \lambda f_{p r f}$. Therefore, detection of higher velocities could be possible by increasing $f_{p r f}$ beyond $5 \mathrm{kHz}$. Fig. 3 shows the estimated mean velocity profiles of the three components from the centre of the full estimated volume from the measured data. The RSD values for $\left(v_{x}, v_{y}, v_{z}\right)$ were $(5.03,4.87,1.27) \%$ and the RBs were $(5.35,3.02,1.00) \%$. The estimator performs almost similarly on measured and simulated data. There is a small increase in the calculated metrics compared with the same case in the simulated data with the RSDs of $(2.26,3.46,0.78) \%$ and the RBs of ($1.39,-0.03,-0.08) \%$. The higher RSDs and RBs for the

experiments are likely due to the presence of noise in the measurements. The results presented in Fig. 3 show that the estimates follow the expected profiles. A parabolic profile is observed in the $x$ direction, and the estimated velocity is close to zero in the other two directions. The estimated small velocity in $y$ and $z$ directions could be due to the non-quadratic probe aperture [5], [14]. Overall, the estimation results on the simulated and also the measured data demonstrate that the TVI at a high volume rate of $500 \mathrm{~Hz}$ is achievable with high accuracy by the proposed recursive interleaved SA sequence along with the TO cross-correlation based velocity estimator.

\section{CONCLUSion}

A 3-D TVI technique using a matrix transducer array and a directional transverse oscillations synthetic aperture velocity estimator was investigated using simulations and experiments on a flow-rig. The flow-rig was positioned along the $x$ direction. Different peak velocities were considered in simulations and the estimations were obtained with RB and RSD less than $-13.3 \%$ and 5\%, respectively. The experimental results confirm the possi- 


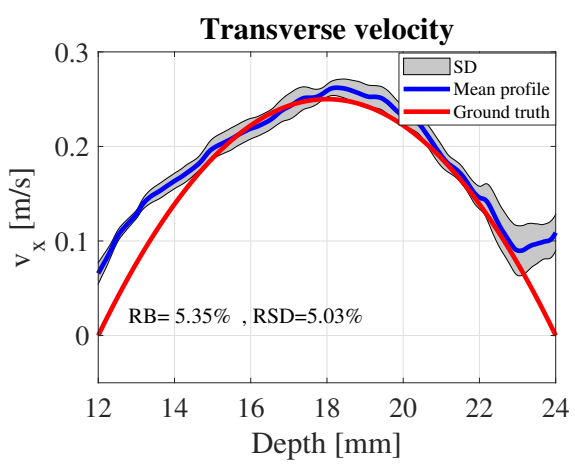

(a)

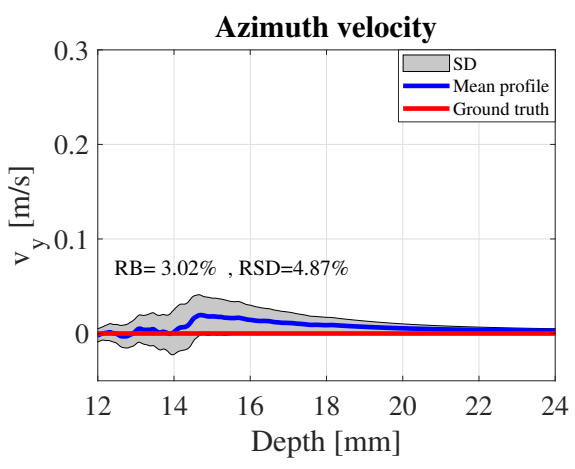

(b)

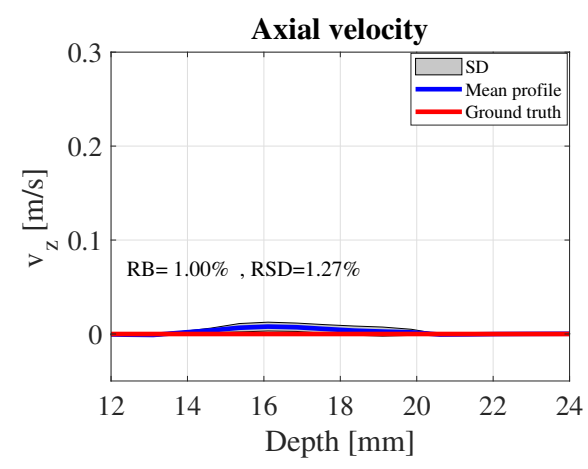

(c)

Fig. 3: Estimated tensor velocity components for the flow-rig with a parabolic flow profile along the $x$ direction. Profiles are from the centre of the volume. (a) $v_{x}$, (b) $v_{y}$, (c) $v_{z}$. The true profiles are in red, the mean estimates are shown in blue and the gray shade is the standard deviation calculated for the 25 estimated velocity profiles.

bility of doing high volume rate TVI in a 3-D volume in practice with high accuracy. The TVI is performed with a volume rate of $500 \mathrm{~Hz}$, which makes it possible to visualize rapid fluctuations in flow. Additionally, the provided continuous data allows for capturing very low velocities.

\section{REFERENCES}

[1] C. E. Morton and G. R. Lockwood, "Theoretical assessment of a crossed electrode 2-D array for 3-D imaging," in Proc. IEEE Ultrason. Symp., 2003, pp. 968-971.

[2] J. T. Yen, C. H. Seo, S. I. Awad, and J. S. Jeong, "A duallayer transducer array for 3-D rectilinear imaging," IEEE Trans. Ultrason., Ferroelec., Freq. Contr., vol. 56, no. 1, pp. 204-212, 2009.

[3] C. E. M. Démoré, A. Joyce, K. Wall, and G. Lockwood, "Realtime volume imaging using a crossed electrode array," IEEE Trans. Ultrason., Ferroelec., Freq. Contr., vol. 56, no. 6, pp. 1252-1261, 2009.

[4] M. J. Pihl and J. A. Jensen, "A transverse oscillation approach for estimation of three-dimensional velocity vectors. Part I: Concept and simulation study," IEEE Trans. Ultrason., Ferroelec., Freq. Contr., vol. 61, pp. 1599-1607, 2014.

[5] M. S. Wigen, S. Fadnes, A. Rodriguez-Molares, T. Bjåstad, M. Eriksen, K. H. Stensæth, A. Støylen, and L. Løvstakken, "4-D intracardiac ultrasound vector flow imaging-reasibility and comparison to phase-contrast MRI," IEEE Trans. Med. Imag., vol. 37, no. 12, pp. 2619-2629, December 2018.

[6] M. Correia, J. Provost, M. Tanter, and M. Pernot, "4D ultrafast ultrasound flow imaging: in vivo quantification of arterial volumetric flow rate in a single heartbeat," Phys. Med. Biol., vol. 61, no. 23, pp. L48-L61, 2016.

[7] J. Provost, C. Papadacci, C. Demene, J.-L. Gennisson, M. Tanter, and M. Pernot, "3-d ultrafast Doppler imaging applied to the noninvasive mapping of blood vessels in vivo," IEEE Trans. Ultrason., Ferroelec., Freq. Contr., vol. 62, no. 8, pp. 14671472, 2015.

[8] C. Papadacci, V. Finel, O. Villemain, G. Goudot, J. Provost, E. Messas, M. Tanter, and M. Pernot, " $4 \mathrm{~d}$ simultaneous tissue and blood flow doppler imaging: revisiting cardiac doppler index with single heart beat 4d ultrafast echocardiography," Phys. Med. Biol., vol. 64, pp. 1-10, 2019.

[9] M. D. Fox, "Multiple crossed-beam ultrasound Doppler velocimetry," IEEE Trans. Son. Ultrason., vol. SU-25, pp. 281286, 1978.
[10] V. L. Newhouse, K. S. Dickerson, D. Cathignol, and J.-Y. Chapelon, "Three-dimensional vector flow estimation using two transducers and spectral width," IEEE Trans. Ultrason., Ferroelec., Freq. Contr., vol. 41, pp. 90-95, 1994.

[11] I. A. Hein, "Triple-beam lens transducers for three-dimensional ultrasonic fluid flow estimation," IEEE Trans. Ultrason., Ferroelec., Freq. Contr., vol. 42, pp. 854-869, 1995.

[12] S. W. Smith, H. G. Pavy, and O. T. von Ramm, "High speed ultrasound volumetric imaging system - Part I: Transducer design and beam steering," IEEE Trans. Ultrason., Ferroelec., Freq. Contr., vol. 38, pp. 100-108, 1991.

[13] J. Provost, C. Papadacci, J. E. Arango, M. Imbault, M. Fink, J. L. Gennisson, M. Tanter, and M. Pernot, "3-D ultrafast ultrasound imaging in vivo," Phys. Med. Biol., vol. 59, no. 19, pp. L1-L13, 2014.

[14] M. B. Stuart and J. A. Jensen, "3-D directional transverse oscillations synthetic aperture vector flow imaging with a 1024 element matrix probe," in Proc. IEEE Ultrason. Symp., 2019, pp. $1-4$.

[15] J. A. Jensen and N. B. Svendsen, "Calculation of pressure fields from arbitrarily shaped, apodized, and excited ultrasound transducers," IEEE Trans. Ultrason., Ferroelec., Freq. Contr., vol. 39, no. 2, pp. 262-267, 1992.

[16] J. A. Jensen, "Field: A program for simulating ultrasound systems," Med. Biol. Eng. Comp., vol. 10th Nordic-Baltic Conference on Biomedical Imaging, Vol. 4, Supplement 1, Part 1, pp. 351-353, 1996.

[17] S. I. Nikolov and J. A. Jensen, "In-vivo synthetic aperture flow imaging in medical ultrasound," IEEE Trans. Ultrason., Ferroelec., Freq. Contr., vol. 50, no. 7, pp. 848-856, 2003.

[18] J. A. Jensen, "Estimation of high velocities in synthetic aperture imaging: I: Theory," IEEE Trans. Ultrason., Ferroelec., Freq. Contr., vol. 66, no. 6, pp. 1024-1031, 2019.

[19] L. Ratsimandresy, P. Mauchamp, D. Dinet, N. Felix, and R. Dufait, "A $3 \mathrm{MHz}$ two dimensional array based on piezocomposite for medical imaging," in Proc. IEEE Ultrason. Symp., 2002, pp. 1265-1268.

[20] J. A. Jensen, H. Holten-Lund, R. T. Nilsson, M. Hansen, U. D. Larsen, R. P. Domsten, B. G. Tomov, M. B. Stuart, S. I. Nikolov, M. J. Pihl, Y. Du, J. H. Rasmussen, and M. F. Rasmussen, "SARUS: A synthetic aperture real-time ultrasound system," IEEE Trans. Ultrason., Ferroelec., Freq. Contr., vol. 60, no. 9, pp. 1838-1852, 2013. 